\title{
İstanbul'un Yağmur Suyu Taşkınlarına Karşı Yeşil Teras Çatıların Önleyici Rolü
}

\author{
Deniz YILMAZ ${ }^{* 1}$ \\ ${ }^{1}$ Munzur Üniversitesi, Mühendislik Fakültesi, İnşaat Mühendisliği Bölümü, Tunceli
}

Geliş tarihi: 02.06.2016 Kabul tarihi: 23.11.2016

Öz

İstanbul nüfusunun son yarı yüzyılda hızlı bir şekilde artması, konut ve kentleşmede sorunlara neden olmuştur. Sorunun hızlı yapılaşma yaklaşımıyla giderilmeye çalışılması da ayrıca farklı sorunları beraberinde getirmiş̧ir. Bu sorunların en önemlilerinden biri kentteki yağmur suyu taşkınlarıdır. Bu nedenle her şiddetli yağmur sonrası İstanbul'un birçok yerinde taşkınlar oluşmaktadır. Kent için maddi ve manevi zarara neden olan bu taşkınlar, ekolojik açıdan da ciddi bir kirlilik yaratmaktadır. Yağmur suyu taşkınlarında, yüzey suyunun çoğalması önemli bir faktördür. Aşırı yapıllaşma ile yaratılan geçirimsiz tabakadan dolayı toprak yüzeyi altına sızma imkânı bulamayan yağmur suyu, kaçınılmaz olarak yüzeyde akmakta ve artarak kentin en düşük noktalarında birikmektedir. Suyun aşırı şekilde biriktiği bu tür noktalarda şebekelerin yetersiz kalması, taşkınların meydana gelmesi kaçınılmaz olmaktadır. Bu noktada, yapılaşmada "Yeşil teras çatı" denilen sistemlerin yaygınlaştırılarak kullanılması, bu tür taşkın problemlerinin azaltılmasına katkı sağlayacaktır. Bu makalede İstanbul kentinde yağmur suyundan kaynaklanan taşkın problemlerine yeşil çatı sistemlerinin nasıl önleyici bir fonksiyon üstlenebileceği ele alınmaktadır.

Anahtar Kelimeler: İstanbul, Kentleşme, Yağmur suları, Taşkın, Yeşil çatı

\section{Preventive Role of Green Flat Roofs Against Rain Water Floods of İstanbul}

\begin{abstract}
A rapid increase of the provincial population of Istanbul in the last half century has caused problems of housing and urbanization. Despite trying to resolve this problem with the rapid construction, it has led to many problems. The rain floods in the city are the most important ones. For this reason, floods occur in many parts of Istanbul after heavy rainfall. These floods, which is responsible of material and moral damages caused to the city, also creates from ecological point of view serious pollutions. One of the important factors that cause rain water floods is the proliferation of superficial rainwater. Because rain water cannot infiltrate into the soil due to impermeable constructions, it flows at the surface and the amount of surface rain water increases with increasing construction on the area. Rain water gathered at the lowest point of the town basin. Since an excessive load on the rain water networks occurs in these
\end{abstract}

\footnotetext{
*Sorumlu yazar (Corresponding author): Deniz YILMAZ, dyilmaz@munzur.edu.tr
} 
places, the surface water cannot be removed and causes floods. In this area, using systems called "Green roof terrace" in construction will contribute to the reduction of such flooding problems. This article describes how green roof could play a preventive function to the flood problems caused by rainwater in Istanbul province.

Keywords: İstanbul, Urbanization, Rainwater, Floods, Green roofs

\section{GİRiş}

Geçen son yarı yüz yıl içinde, İstanbul şehri yoğun bir göç akımına tanık olmuştur. 1980’de İstanbul nüfusu 4,7 milyon olarak tespit edilmiştir. 2000'li yıllarda ise bu nüfus iki katı olmuştur [1]. Buna paralel olarak konutlaşma hılı ve düzensiz bir şekilde İstanbul'un geniş alanlarını kapsamıştır. Avrupa yakasında şehirleşme ve sanayileşme yüzeyleri 1987'de 13460 ha'dan 2001 yillında 30750 ha olmuştur [2]. Bunun yanı sıra ormanlık, tarım ve boş doğal alanlar gittikçe azalmıştır [3]. $\mathrm{Bu}$ hızlı büyüme kendisi ile birlikte birçok problem getirmiştir. İstanbul su havzaların yapılaşmadan dolayı suyun kirlenmesine sebep olmuştur ve su temini için ciddi zorluluklar yaratmıştır. Küçük Çekmece su havzası bunun bariz bir örneğidir [4]. Yapılanmanın bir başka etkisi kentsel sıcak adadır. İstanbul ile ilgili birçok bilimsel çalışma kentsel sıcak adanın var oluşunu tespit etmiştir [5-7]. Sicak hava adası kent merkezlerinde ortalama sıcaklığı doğal bir ortama göre birkaç derece yükseltmektedir. Buda enerji tüketimini artırmakta (klima kullanımı gibi) ve yaşam konforunu etkilemektedir [8-9]. Bu nedenle yapılaşma ve sanayileşmeden dolayı İstanbul'un havası kirlenmektedir [10-12].

Sıralanmış olan bu sorunların yanı sıra, İstanbul'un en önemli problemlerden bir tanesi taşkınlardır. 1989 ile 2009 yılları arası 59 tane taşkın İstanbul'da olmuştur [13]. 11 Ağustos 2004 tarihinde İstanbul'un Sarıyer Kozdere yatağında oluşan taşkın 3 kişinin hayatına mal olurken, 300 civarında konuta da zarar vermiştir [14]. Plansız şehirleşmenin devam etmesi, küresel iklim değişimi ile birlikte şiddetli yağmurların ve firtınaların gelecek yıllarda çoğalması, kaçınılmaz olarak taşkın sayısını ve tahribatı artıracaktır. Özellikle birleşik atık su şebekelerinde oluşan taşkınlar, ayni zamanda suların kirlenmesine ve çevre tahribatına neden olmaktadır. Genellikle eski kentleşme alanlarında mevcut "birleşik sistem" şebekelerinde bir arada taşınan yağmur suları ve evsel atıklar, şiddetli yağmurlarda artan debi yükleri nedeniyle şebekelerde patlak ve taşkınlar oluşmakta, atık su ve yağmur suyunun karışmasına neden olmaktadır. Birleşik sistemin bulunduğu alanlarda arıtma tesislerinin de verimli çalıştığ1 söylenemez. Şiddetli yağmurlarda (arıtma tesislerine zarar vermemek için) atık suların doğrudan doğal ortama verilmesinin tercih edilmesi nedeniyle arıtma işleminin gerçekleşmesine engel olunmakta ve çevre kirletilmektedir. Öte yandan yeni yerleşim alanlarda ise "ayrlk sistemler" mevcuttur. Bu yerlerde yağmur suları ve evsel atıklar ayrı taşınmaktadır. Ayrık sistemlerde taşkınlar yağmur suyu şebekesinde oluşur ve havza üzerindeki kirlilik yüzeysel yağmur sularını kirletir. Özellikle sanayi bölgelerin deki taşkınlar ciddi ekolojik tahribata neden olmaktadır.

Diğer bir husus ise yoğun kent ortamlarında geçirgen zeminin kısıtlı olması nedeniyle zemin yüzeyi altına sızma imkânı bulamayan yağmur sularının taşkına sebep olması sorunudur. $\mathrm{Bu}$ noktada, taşkınlara önleyici veya riskini ve tahribat seviyesini azaltacak en önemli etken, yağmur suyunun toprağa temas etmesini sağlamaktadır. Yeşil yerlerin korunması, zeminlerin geçirgenliğini artırılması gibi çözümler taşkın riskini azaltır. Bir başka çözüm ise var olan yağmur su şebekesinin kapasitesini artırmaktır. Ancak eski kentlerde, yağmur su şebekesi alt yapısı var olan İstanbul gibi şehirlerde şehri yeniden dizayn etmek oldukça problemlidir. $\mathrm{Bu}$ anlamda, belediyeler, yağmur suyunu toplayan şebekenin kapasite artırımını, çok maliyetli ve çevreye verilecek rahatsızlık dolayı nedeniyle genellikle uygulamaktan kaçınmaktadır. Bunun yerine yağmur suyunu tutacak veya zemine sıdıracak alternatif tampon sistemlerine ihtiyaç 
duyulmaktadır. Yeşil çatılar denilen sistem bu problemin çözülmesine katkı sunabilmektedir [15-16]. Paris, Nantes ve Berlin gibi birçok Avrupa belediyesi yeşil çatılara ödenek vererek teşvik etmektedir. Konu bu bağlamda değişik boyutlarıyla ele alınarak İstanbul için uygulanabilirliği irdelenmiştir.

\section{YEŞIL TERAS ÇATILARIN YAĞMUR SUYUNU TUTMA ÖZELLÍKLERİ}

Yeşil teras çatılar hafif seyrek sistemlerdir, bakım hariç üzerinde gezilemez. Teras terimini düz çatı olarak algılamak gerekmektedir. Üzerinde gezine bilinen yeşil çatılara "Bahçe Yeşil Çatı” adı verilir ve bunlar yeşil teras çatılarına göre ağır yüklü sistemlerdir. Yeşil teras çatıların bileşenleri suni toprak katmanı ve kuraklığa dayanıklı bir bitki örtüsü ile oluşturulmaktadır (Şekil1).

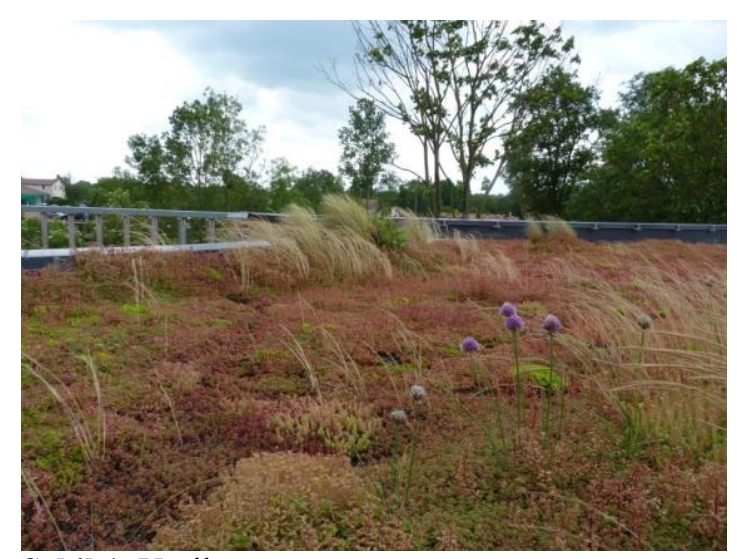

Şekil 1. Yeşil teras çatı

Çatı üzerinde olan bu katman ve bitki örtüsü yağmur suyunu depolama veya tutma fonksiyonunu alabilir. Yeşil çatıların katmanın karakteristiklerinden bir tanesi bol gözenekli olmasıdır. Genellikle Puzolan volkanik taşı ile suni gübre karışımı ile oluşur. Bu da sistemin klasik bir zemine göre daha hafif olmasını sağlar. Yağmur esnasında yeşil çatılar bir sünger rolünü görmektedir. Sistem, yağmur sularını tutar, gözenekleri dolduğu zamanda su süzülerek drenaj tabakasından çatı oluklarına ve yağmur su şebekesine gider. Bu sayede şiddetli yağmurlarda yeşil çatılara gelen yağmur suları tutulur ve belli bir süre sonra şebekeye gönderilir. Böylelikle şebekelerdeki yağmur yükü hafiflemekte, debi pikleri düşmekte ve taşkın riski azalmaktadır [17-18].

Yeşil çatıların yağmur suyunu tutma kapasitesi, yağmur miktarının yüzde kaçını tutabilmesi ile ilişkilidir. Bu veri çoğu zaman yıllık yağmura göre verilir ve yeşil teras çatı sistemlerinde değişik yağmur suyu tutma kapasiteleri ölçülür. Yapılan araştırma ve değerlendirmelere göre bu değer, Almanya'da \%27 ile \%81 arasında değişirken [9], Amerika'nın Chicago, Philadelphia ve Portland şehirlerinde \%65 [19], Fransa'nın Nantes şehrinde $\% 72,8$ ile \%80,2 arasında [20], İtalya'da Genova kenti için ise \%51 olarak bulunmuştur [21]. İstanbul için yapılan bir araştırmada ise yeşil çatının standart bir çatıya göre \%43 daha fazla yağmur suyu tuttuğu tespit edilmiştir [22]. Görüldüğü üzere, Yeşil çatıların yağmur suyunu tutma değerleri, sistemin oluştuğu katmanlar ve iklim koşullarına göre değişmektedir [23]. Bu anlamda, bitki örtüsünü taşıyan katmanın kalınlığ1, bitkinin türü, sistemde su rezervuarlarının olup/olmaması, sistemin yaşı, yağmurun türü (şiddetli yağmur veya hafif sağanaklı), sistemin su doluluk oranı, yaz ve kış gibi iklimsel değişimler yeşil teras çatıların yağmur suyunu tutma değerlerini etkilediğini söylemek mümkündür.

\section{YEŞİL ÇATILARIN DİĞER FONKSIIYONLARI}

Yeşil çatıların birçok alanda faydalı olması durumu, kaçınılmaz olarak bu alanda birçok bilimsel çalışmanın yapılmasını sağlamıştır. Örneğin bu çalışmalardan biri, Şehir ortamlarında yeşil çatıların hava sıcaklığını düşürdüğünün tespitidir [24]. Yalıtımsız yapılarda, yeşil çatıların 1S1 yalıtım görevini yapabildiği, ancak bunun geçerliği kuru ortam ile sınırlı olduğudur. Bunun sebebin ise toprak gözenekleri su ile dolduğu zaman, yeşil teras çatı enerji bakımından taşıyıcı olur ve iç mekân ısısını dışarıya aktarmasıdır [25]. Bunun yanı sıra yeşil yüzeylerin, yani bitkilendirilmiş alanların şehir üzerindeki sıcak ada üzerinde pozitif etkileri olduğu da belirtilir 
[8-9,26]. Bu duruma ilişkin Türkiye'de yapılan bazı çalışmalarda, 1Sı bakımından yeşil çatıların pozitif rol oynadığı özelikle vurgulanır [27-28]. Ağaçlar ve yeşil bitkiler terlediğinden havayı yumuşatır ve klima gibi havayı soğutmak için ihtiyaç duyulan enerji tüketimini azaltmaktadır [29]. Ayrıca yeşil çatılar, kent merkezlerine biyo çeşitlilik katar, kentin estetik görünümüne ve ekolojik kent olmasına katkı sağlar.

\section{4. İSTANBUL İÇIN DEĞERLENDİRME}

İstanbul'da yeşil çatılar, büyük alış veriş merkezleri, lüks ve pahalı binaların üzerinde estetik, ekolojik yapı görünümü sunmak ve yapılara değer katma amaçlı olarak yapıldığ 1 görülmektedir. $\mathrm{Bu}$ sistemlerin birçoğunun bahçe çatı teras ve ağır yüklü sistemler olduğunu söylemek mümkündür. Bu makalede sözü edilen teras yeşil çatılar, İngilizcede "extended flat green roof" olup hafif yüklü sistemlerdir. Üzerinde bakım ihtiyaçları dışında yürünmez. Dünya'daki bu hafif yüklü teras yeşil çatıların suni toprak katmanın kalınlığı $3 \mathrm{~cm}$ ile $12 \mathrm{~cm}$ arası değişmektedir. Teras bahçe çatılarında ise bu kalınlık $30 \mathrm{~cm}$ ile $150 \mathrm{~cm}$ arası değişmektedir. Ayrıca bitkilerin büyümesi için oluşan bu suni ortamın kütlesel ağırlığı bir klasik tarım toprağının ağırlığından 2,5-3 kat daha azdır. Hafif olduğundan, yeşil çatılar İstanbul'daki birçok binanın statik yükünü etkilemeyecek sistemler olarak görülebilir. Belirtildiği gibi yeşil çatıların yağmur suyu tutma kapasitesini birçok faktör etkilemektedir. Bunun için Türkiye şartlarına uygun bir yeşil çatı tasarımı gerekmektedir. Bu da yeşil çatıyı oluşturacak suni ortam malzemelerinin ve bitkilerin yerel olmasıyla birlikte, yeşil çatı kalınlığını ve yeşil çatının yaratacağı statik yükü İstanbul yapılarının kaldırabileceği ölçütlerde tasarlanmasiyla mümkün olabilmektedir. Kuşkusuz tasarlanacak bu yeşil çatının İstanbul iklimindeki yağmur suyunu tutma karakteristikleri tespit edilerek yapılması gerekir. Bu bağlamda tasarımı kabul edilen bir yeşil çatının deneysel amaçlı olarak inşa edilmesi ve en az bir yıl iklim şartlarına maruz bırakılarak, yağmur suyunu tutma kapasitesinin ölçülmesi önemlidir [20]. Bu bağlamda İstanbul kentinin yoğun ve hızlı şehirleşme bölgelerinde coğrafi bilgi sistemi ile çatıların yüzey alanlarının tespit edilerek, yeşil çatıya dönüştürülme potansiyeline sahip çat1 oranları belirlenir ve sayısal modelleme ile bunun yağmur suyu şebekesi üzerindeki etkileri araştırılır. $\mathrm{Bu}$ araştırmaların sonucuna göre yeşil çatıların şehir hidrolojisi bakımından pozitif etkisi böylelikle sayısal ortamda gösterilmiş olunur [30].

\section{SONUÇ}

Türkiye'de yeşil çatılarla ilgili bilimsel çalışmalar az sayıda olmakla birlikte, kentlerin yağmur suyu problemleri ve çözümüne ilişkin araştırma ve çalışmaların ne yazık ki yeterli düzeyde olmadığ 1 görülmektedir. Öte yandan mevcut çatıların yeşil çatıya dönüştürülmesi veya yeni yapılara entegre edilmesinin önündeki en büyük engelin ekonomik olduğu anlaşılmaktadır. Bu durum İstanbul için irdelendiğinde; bu yönden Büyükşehir ve ilçe belediyelerinin teşvik politikası oluşturması, diğer karar mekanizmalarını teşvik vermeleri ve ikna edici bilimsel çalışmaların yapılması önemli bir gereklilik olduğu anlaşılmaktadır. Diğer önemli bir husus ise yeşil çatıların tekniğine uygun yapılması için gerekli altyapı formasyonu, teknik şartname ve mevzuatın tamamlanması ve işlerliğinin sağlanmasıdır. Teknik şartname ve mevzuatına uygun şekilde yaygınlık kazanacak yeşil çatı uygulamalarının bu anlamda, uzun vadede İstanbul kentine faydalı olacağı ve çağdaş, sürdürülebilir kent olma vizyonunu kazandıracağını belirtmek mümkündür.

\section{KAYNAKLAR}

1. Kaya, S., Curran, P.J., 2006. Monitoring Urban Growth on the European Side of the Istanbul Metropolitan area: A Case Study. International Journal of Applied Earth Observation and Geoinformation 8(1), 18-25.

2. Kaya, S., 2007. Multi Temporal Analysis of Rapid Urban Growth in Istanbul Using Remotely Sensed Data. Environmental Engineering Science 24(2), 228-233.

3. Geymen, A., Baz, I., 2008. Monitoring Urban Growth and Detecting Land-Cover Changes on 
the Istanbul Metropolitan Area. Environmental Monitoring and Assessment 136(1-3), 449-459.

4. TMMOB Çevre Mühendisler Odası İstanbul Şubesi. İstanbul Avrupa Yakası Su Havzaları Teknik Tespit Raporu, 27 Ekim 2014.

5. Karaca, M.,Tayanç, M., Toros., M., 1995. Effects of Urbanization on Climate of Istanbul and Ankara. Atmospheric Environment 29(23), 3411-3421.

6. Ezber, Y., Lutfi Sen, O., Kindap, T., Karaca, M., 2007. Climatic Effects of Urbanization in Istanbul: a Statistical and Modeling Analysis. International Journal of Climatology, 27(5), 667-679.

7. Yalcin, T., Yetemen, O., 2009. Local Warming of Ground Waters Caused by the Urban Heat Island Effect in Istanbul, Turkey. Hydrogeology Journal, 17(5), 1247-1255.

8. Bass, B.,Stull, R., Krayenjoff, S., Martilli, A., 2002. Modelling the Impact of Green Roof Infrastructure on the Urban Heat Island in Toronto. The Green Roof Infrastructure Monitor, 4, 2-3.

9. Mentens, J., Raes, D., Hermy, M., 2006. Greenroofs as a tool for Solving the Rain Water Run off Problem in Theurbanized 21st Century? Landscapeand Urban Planning, 77, 217-226.

10. Elbir, T., Müezzinoğlu, A., Bayram, A., 2000. Evaluation of Some Air Pollution Indicators in Turkey. Environment International, 26(1), 510.

11. Akkoyunlu, A., Erturk, F., 2002. Evaluation of air Pollution Trends in Istanbul. International Journal of Environment and Pollution, 18(4), 388-398.

12. Onkal-Engin, G., Demir, I., Hiz, H., 2004. Assessment of Urban Air Quality in Istanbul Using Fuzzy Synthetic Evaluation. Atmospheric Environment, 38(23), 3809-3815.

13. Turoğlu, H., 2011. Flash Floods and Floods in Istanbul, İstanbul'daki Sel ve Taşkınlar. Ankara Üniversitesi Çevrebilimleri Dergisi, cilt1 say13:39-46.

14. Celik, H.E., Aydin, A., Esin, I., Coskun, H.G., Alganci, U., Usta, G., Cigizoglu, H.K., 2009. The Causes of the Floods on the Streams Flowing to Bosphorus and the Precautions Needed: Kozdere Case Study. In Remote
Sensing for a Changing Europe: Proceedings of the $28^{\text {th }}$ Symposium of the European Association of Remote Sensing Laboratories, Istanbul, Turkey, 2-5 June 2008 (p. 326). IOS Press.

15. Monterusso, M.A., 2004. Runoff Water Quantity and Quality From Green Roof Systems. Acta Horticultirae, 639, 369-376.

16. Van Woert, N.D., Rowe, D.B., Andresen, J.A., Rugh, C.L., Fernandez, R.T., Xiao, L., 2005. Green Roof Stormwater Retention. Journal of Environment Quality, 34, 1036-1044.

17.Simmons, M.T., Gardiner, B., Windhager, S., Tinsley, J., 2008. Green Roofs are not Created Equal: the Hydrologic and Thermal Performance of Six Different Extensive Green Roofs and Reflective and Non-Reflective Roofs in a Sub-Tropical Climate. Urban Ecosyst. 11 (4), 339-348.

18. Versini, P.A., Ramier, D., Berthier, E., de Gouvello, B., 2015. Assessment of the Hydrological Impacts of Green Roof: from Roof Scale to Basin Scale. Journal of Hydrology, 524, 562-575.

19. Scholz-Barth, K., 2001. Green Roofs: Stormwater Management from the top down. Environmental Design \& Construction, 4, 6369.

20. Yilmaz, D., Sabre, M., Lassabatere, L., Dal, M., Rodriguez, F., 2016. Storm Water Retention and Actual Evapotranspiration Performances of Experimental Green Roofs in French Oceanic Climate. European Journal of Environmental and Civil Engineering, 20(3), 344-362.

21. Palla, A., Gnecco, I., Lanza, L., 2010. Hydrologic Restoration in the Urban Environment using Green Roofs. Water, 2, 140-154.

22. Ekşi, M., 2013. A Field Study to Evaluate the Runoff Quantity and Stormwater Retention of a Typical Extensive Green Roof in Bahçeköy, Istanbul. Environment Protection Engineering, 39(4),79-89.

23. Czemiel Berndtsson, J., 2010. Green Roof Performance Towards Management of Runoff Water Quantity and Quality: A Review. Ecological Engineering, 36, 351-360. 
24. Santamouris, M., 2014. Cooling the Cities-a Review of Reflective and Green Roof Mitigation Technologies to Fight Heat Island and Improve Comfort in Urban Environments. Solar Energy, 103, 682-703.

25. Castleton, H.F., Stovin, V., Beck, S.B.M., Davison, J.B., 2010. Green Roofs; Building Energy Savings and the Potential for Retrofit. Energy and Buildings, 42(10), 1582-1591.

26. Dimoudi, A., Nikolopoulou, M., 2003. Vegetation in the Urban Environment: Microclimatic Analysis and Benefits. Energy and Buildings, 35, 69-76.

27. Türkerı, N., Altun, M.C, Göçer, C., 2011. İstanbul'da Mevcut Çatı Sistemi ile Bitkilendirilmiş Çatı Sistemi Isıl Performanslarının Karşılaştırılmalı Değerlendirilmesi, Megaron 6(1), 21-29.

28. Ekşi, M., Uzun, A., 2013. Investigation of Thermal Benefits of an Extensive Green Roof in Istanbul Climate. Scientific Research and Essays 8(3), 623-632.

29. Akbari, H., Konopacki, S., 2005. Calculating Energy-Saving Potentials of Heat-Island Reduction Strategies. Energy Policy, 33, 721-756.

30. Versini, P.A., Ramier, D., Berthier, E., De Gouvello, B., 2015. Assessment of the Hydrological Impacts of Green Roof: From Building Scale to Basin Scale. Journal of Hydrology, 524, 562-575. 